\title{
Modelagem da dinâmica de uso e ocupação da terra no município de Pombal - PB
}

\section{Modeling of the use of dynamic and land occupation in the municipality of Pombal - PB}

\author{
Juciê de Sousa Almeida ${ }^{1}$; Wellington Ferreira de Melo ${ }^{2}$; Anderson Bruno Anacleto de Andrade ${ }^{3}$; Hamanda Gelça Araújo \\ Costa Saldanha ${ }^{4}$; Luma Michelly Soares Rodrigues ${ }^{5}$
}

Resumo: O presente estudo objetivou aplicar álgebra de mapas, por meio de sobreposição booleana na determinação da dinâmica do uso e ocupação do solo, realizado na cidade de Pombal, Paraíba - Brasil. Foram adotados procedimentos de análise espacial utilizando o SIG/SPRING-5.2, duas imagens 2002/2012 foram registradas, filtradas, classificadas e posteriormente cruzadas por inferência booleana. O principal objetivo da pesquisa foi verificar a dinâmica de uso e ocupação do solo no município de Pombal-PB, cruzando imagens de diferentes sensores orbitais e analisando a dinâmica espacial e temporal da paisagem. Após a análise, constatou-se que houve um crescimento das atividades agropecuárias de 20,3\%, e 3,1 $\%$ das áreas com Agricultura Irrigada as margens dos rios Piancó e Piranhas. A Caatinga Estépica Arborizada e Florestada avançaram 23,0 \% sobre as demais coberturas e uso do solo, além de 3,8\% das áreas sofreram regeneração, portanto, a qualidade da paisagem teve uma sensível piora em termos ambientais, o que foi determinado pelo aumento das áreas com solo exposto degradado e aumento do nível de alterações antrópicas.

Palavras-chaves: Dinâmica; Paisagem; Análise Espacial.

Abstract: This study aimed to apply map algebra by means of boolean overlap in determining the dynamics of the use and occupation of land, in the city of Pombal, Paraíba - Brazil. Spatial analysis procedures were adopted using the SIG/SPRING5.2, two images 2002/2012 were recorded, filtered, sorted and then crossed by inference boolean. The main objective of the research was to investigate the dynamics of use and occupation of land in the municipality of Pombal-PB, crossing images from different satellite sensors and analyzing spatial and temporal dynamics of the landscape. After analysis, it was found that there was an increase of agricultural activities 20.3\%, and 3.1\% of the areas with Irrigated Agriculture margins of Piancó and Piranhas rivers. The Caatinga Steppe Tree and Woodland advanced $23.0 \%$ on other types of coverage and land use, as well as $3.8 \%$ of the areas have experienced regeneration, thus the landscape quality had a significant worsening in environmental terms, which was determined by increase in exposed areas with degraded soil and increase the level of environmental disruption.

Key words: Dynamic; Landscape; Spatial Analysis

\footnotetext{
*Autor para correspondência

Recebido para publicação em 23/01/2015; aprovado em 26/02/2015

${ }^{1}$ Mestre em Sistemas Agroindustriais, UFCG-Pombal-PB, Professor FIP-Patos/João Pessoa-PB; E-mail: juciesalmeida@gmail.com.

${ }^{2}$ Mestre em Sistemas Agroindustriais, Professor UACC-CCJS-UFCG-Sousa-PB, E-mail: wellingtonabcd@ gmail.com

${ }^{3}$ Graduando em Agronomia , Universidade Federal de Campina Grande. E-mail: bdeandrade3@gmail.com

${ }^{4}$ Licenciada em Geografia pela Universidade Federal do Rio Grande do Norte (UFRN) e Bacharela em Administração pela Universidade Estadual do Rio

Grande do Norte (UERN). E-mail: hamanda.admgeo@gmail.com

${ }^{5}$ Graduada em Administração, UFCG, Sousa-PB, E-mail: luma_michelly@ hotmail.com
} 


\section{INTRODUÇÃO}

O termo uso da terra pode ser entendido como sendo a forma pela qual o homem ocupa o espaço. O levantamento do uso do uso e ocupação da terra é de grande importância na medida em que os efeitos do uso da terra causam degradação no ambiente. Os processos de erosão intensos, as inundações, os assoreamentos desenfreados de reservatórios e cursos d'água são consequências do mau uso do solo. A classificação do uso da terra numa dada região tornou-se um aspecto fundamental para a compreensão dos padrões de organização do espaço (FERREIRA; FILHO, 2009).

A redução da cobertura vegetal natural e a fragmentação dos ecossistemas florestais atinge quase todos os biomas. No caso da caatinga, essa fragmentação é grave, pois constitui um importante fator para o empobrecimento biológico. Além de suas graves consequências para da biodiversidade, compromete ainda uma série de funções dos ecossistemas florestais, incluindo, a conservação dos recursos hídricos (VIANA, 1998).

O uso intensivo dos recursos naturais e o crescimento da população inerentemente estão ampliando os desequilíbrios na relação homem-natureza. A análise da evolução das paisagens é um passo importante para entender a relação homem e o meio ambiente, permitindo estimar mudanças futuras, levando em consideração os acontecimentos do passado (OKA-FIORI; HASUI, 2003).

A análise de uso e ocupação dos solos contribui para a compreender a evolução da paisagem de uma determinada área, ela fornece suporte permanente para a aplicação de propostas de manejo para áreas de preservação permanente (KLEINPAUL et al., 2009). Segundo Rosa (2001), essa análise permite acompanhar a evolução dos padrões da organização do espaço, facilitando a identificação dos impactos ambientais gerados do uso inadequado da terra.

O processo de desmatamento é um problema que vem crescendo a cada ano na região de Pombal, e vem sendo potencializado com o avanço da agropecuária, ocasionando intensificação dos processos erosivos (ALMEIDA, 2012). Com a utilização das geotecnologias, têm-se analisado a qualidade dos elementos de uma determinada paisagem, dessa forma é possível viabilizar um melhor planejamento do uso dos recursos naturais e o manejo da cobertura florestal, avaliando por meio de imagens de diferentes épocas através do geoprocessamento, pode-se aplicar e integrar os diferentes componentes paisagísticos, proporcionando análises espaciais e temporais com qualidade (DÉSTRO; CAMPOS, 2006).

De acordo com Soares et. al., (2011) esses problemas não são exclusividade dos países subdesenvolvidos, os países desenvolvidos também apresentam suas terras afetadas, muitos desses problemas têm surgido por conta das mudanças no meio, portanto é imprescindível manter a cobertura vegetal e recuperar áreas degradadas por desmatamento ou uso inadequado.

A utilização desordenada dos recursos naturais tem promovido ao longo do tempo um cenário de desequilíbrio ambiental em todo mundo, justificado pelo crescimento contínuo e insustentável, decorrente das atividades humanas e provocadas no meio. Neste sentido, para uso sustentável dos recursos da natureza, torna-se necessário um gerenciamento que proporcione uma melhor compreensão da dinâmica do meio ambiente (MOREIRA et al., 2014).
Algumas ferramentas importantes para se detectar e mapear estas mudanças são as imagens de satélites obtidas por plataformas orbitais e os sistemas de informações geográficas. $\mathrm{O}$ sensoriamento remoto tornou-se uma importante fonte de informações para monitorar os recursos da Terra, devido à possibilidade de se adquirir dados sobre grandes extensões geográficas, e assim, possibilitar a partir desses monitoramentos uma melhor compreensão dos processos que ocorrem nestas áreas (FERREIRA; FILHO, 2009).

O avanço decorrente da análise do espaço é subsidiado por importantes ferramentas dentro das geotecnologias que geram ricas informações espaciais, análises temporais, diagnósticos e prognósticos que possibilitam o monitoramento integrado das bacias hidrográficas. O sensoriamento remoto, Sistema de Informação Geográfica (SIG), Global Positioning System (GPS) são alguns exemplos dessas ferramentas que compõe este campo de estudo (LEITE; FERREIRA, 2013).

Este trabalho tem como objetivo verificar a dinâmica do uso e ocupação do solo no município de Pombal-PB a partir do cruzamento com imagens de diferentes sensores orbitais usando LEGAL (Linguagem Espacial de Georreferência Algébrica) analisando a dinâmica espacial e temporal da paisagem de Pombal-PB.

\section{MATERIAL E MÉTODOS}

\section{Caracterização e localização da área de estudo}

A área de estudo é o município de Pombal localizado no Sertão do Estado da Paraíba, entre as coordenadas Latitude: -6.76885, Longitude: $-37.79576^{\circ} 46^{\prime} 8^{\prime \prime} \mathrm{Sul}, 37^{\circ} 47^{\prime}$ $45^{\prime \prime}$ Oeste, possui uma área de $888,80 \mathrm{~km}^{2}$ ou 88.880 ha.

Encontra-se limitada Mesorregião Sertão Paraibano e hoje já faz parte da $10^{\circ}$ microrregião com sede na própria cidade. Limita-se ao norte com os municípios de Santa Cruz, Lagoa e Paulista, leste com Condado, sul com São Bentinho, Cajazeiras, Coremas, e São José da Lagoa Tapada, oeste, com Aparecida e São Francisco (Figura 1).

Figura 1 - Localização do município de Pombal no estado da Paraíba.

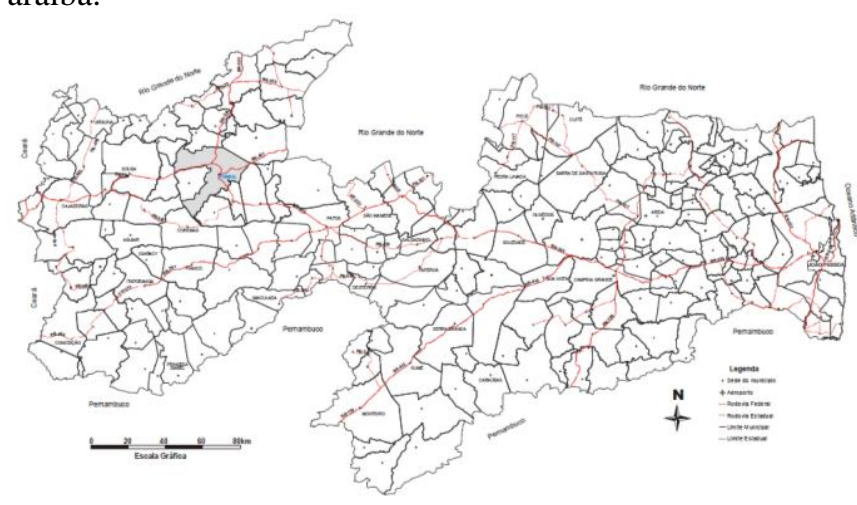

Fonte: BRASIL, 2005

O clima, de acordo a classificação de Köppen, é do tipo Aw', quente, com chuvas de verão-outono, resultantes das frentes de convergência intertropical. A vegetação predominante é a caatinga hiperxerófila, caracterizado por 
extrato arbóreo e/ou, arbustivo de porte variável e caráter xerófilo, com plantas espinhosas, cactáceas e bromeliáceas.

Esta vegetação encontra-se largamente devastada pela ação do homem e, em algumas áreas raleadas, para o aproveitamento com pecuária extensiva. Ás margens do rio Piancó e Piranhas encontram-se estreitas faixas de mata ciliar exploradas economicamente para fins agrícolas.

$\mathrm{Na}$ metodologia utilizou-se do reconhecimento dos padrões visuais dos sensores orbitais, pois esses são variáveis de acordo com os aspectos físicos da paisagem, sendo comparados com reconhecimentos em campo e associados com as informações do uso e ocupação do solo. Foram utilizadas imagens ortorrentificadas do sensor TM-Landsat (NASA, 2000) Bandas 3, 4, 5, ponto 216 e órbita 065, e LIS3-
P6-ResourceSAT Bandas 2, 3, 4, ponto 335, órbita 081, (georreferenciada) (INPE, 2012).

As imagens foram corrigidas no Regeemy 0.2.43, e processadas, filtradas e classificadas no SPRING 5.2, a classificação foi efetuada pelo método pixel a pixel, ou Maxver (Máxima Verossimilhança), foi obtido 9 amostras para cada classe, com desempenho médio acima de $90 \%$. Nas imagens do ResourceSAT, para obter uma composição colorida RGB, as bandas azul e verde, foram geradas por meio de álgebra de mapas com as operações (BLUE $=0.85 *$ B2 $-0.15 * \mathrm{~B} 4$; GREN $=0.65 * \mathrm{~B} 2+0.35 * \mathrm{~B} 4)$, obtendo uma composição em cores verdadeiras, facilitando a obtenção de informações do uso e ocupação do solo referente ao ano de 2012.

Figura 2 - Roteiro dos procedimentos metodológicos adotados na pesquisa.

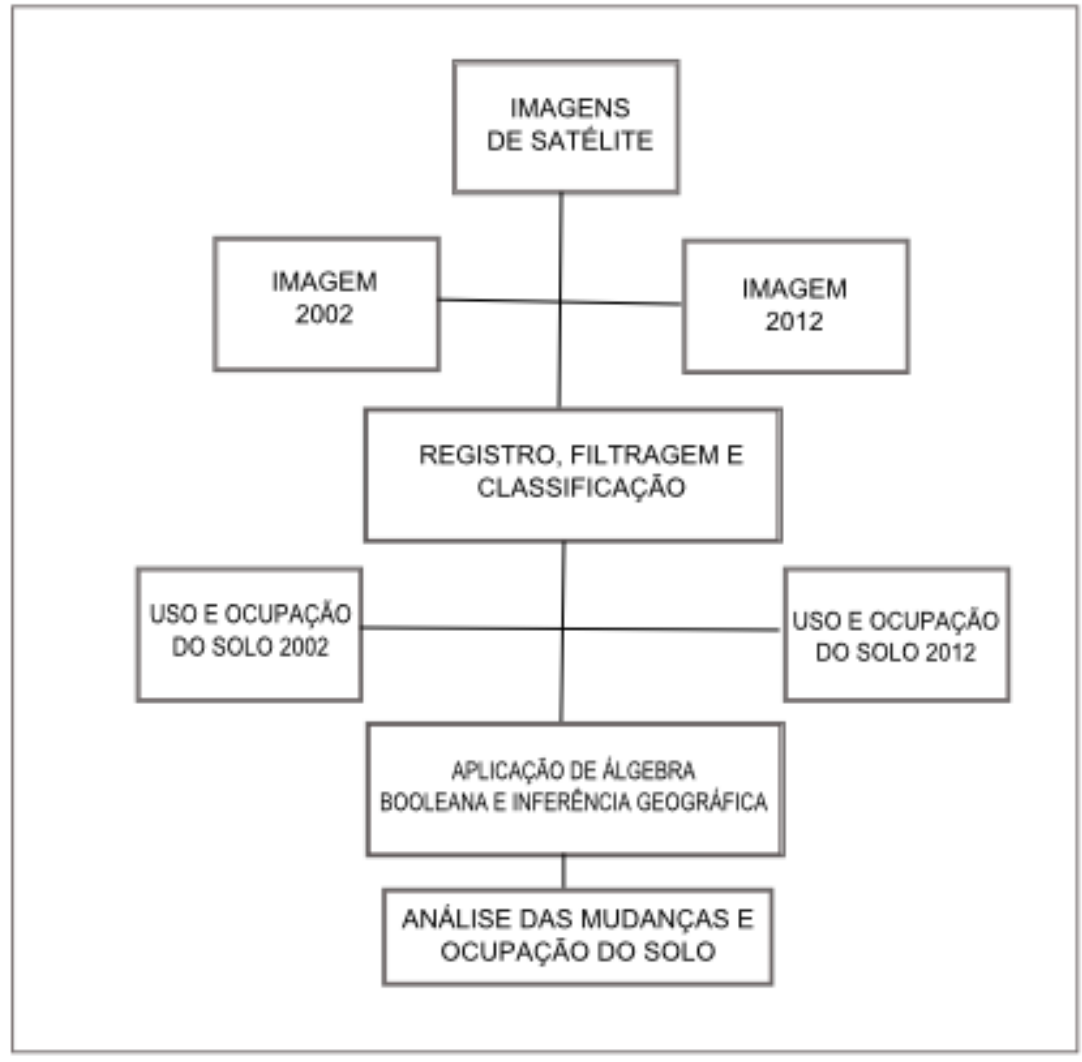

A imagem resultante da sobreposição dos planos de informação foi obtida por cruzamento usando lógica booleana, no ambiente de programação em LEGAL. Dessa forma, cada classe representa uma combinação única de entre as classes de vegetação, agropecuária e solo exposto do município de Pombal-PB.

\section{RESULTADOS E DISCUSSÃO}

Os resultados obtidos a partir do processo de análise espacial demostraram uma redução na cobertura vegetal na área de estudo (Tabela 1), no ano de 2002 os remanescentes florestais formados pela Caatinga Estépica Arborizada apresentavam 35,5\%, e a Caatinga Estépica Florestada manteve recobria $25,6 \%$.

A agropecuária caracterizada pela pecuária extensiva e agricultura de cerqueiro, manteve $27,4 \%$, a agricultura irrigada era praticada em $4,7 \%$ da área de estudo. O principal padrão de uso e ocupação do solo encontrado na área em estudo, também observado em (JUNIOR; ALMEIDA, 2010), foram criações de gado e culturas diversificadas praticadas em pequenas e médias propriedades. 
Tabela 1 - Resumo quantitativo do uso e ocupação do solo no município de Pombal, Paraíba no ano de 2002.

\begin{tabular}{llll}
\hline Classe Temática & Área Total $\left(\mathrm{Km}^{2}\right)$ & Área Total (hectare) & $\%$ da área Total \\
\hline Água & 3,7 & 373,7 & 0,4 \\
Agricultura Irrigada & 41,4 & $4.138,9$ & 4,7 \\
Caatinga Estépica Florestada & 227,4 & $22.744,2$ & 25,6 \\
Caatinga Estépica Arborizada & 315,7 & $31.570,9$ & 35,5 \\
Afloramento & 2,0 & 201,3 & 0,2 \\
Zona Urbana & 55,0 & $5.503,3$ & 6,2 \\
Agropecuária & 242,9 & $24.288,8$ & 27,4 \\
Total & 888,1 & $88.821,1$ & 100 \\
\end{tabular}

Na Tabela 2, no ano de 2012, a Caatinga Estépica Florestada apresentava 4,2 \%, a Caatinga Estépica Arborizada, representando $41,1 \%$ da cobertura, e a Agropecuária, 34,8 \%. A Agricultura Irrigada apresentava 4,2 $\%$, com base na análise de dados, observamos que houve uma redução nas áreas com Caatinga Estépica Florestada, e um aumento das áreas de Caatinga Estépica Arborizada e das atividades agropecuárias. A interpretação das informações geradas permitiu inferir o estado geral das áreas degradadas, o manejo das pastagens adotados pelos pecuaristas apresenta-se como fator potencial na influência dos níveis de degradação (GALDINO et al., 2015).

A utilização da técnica de sobreposição booleana permitiu observar e medir mudanças mais sensíveis na paisagem, à álgebra de mapas permitiu modelar as mudanças na dinâmica da paisagem que não são possíveis de perceber pelos padrões obtidos nas imagens orbitais. Dessa forma identificamos e medimos o crescimento das atividades agropecuárias, perda e regeneração da cobertura vegetal, dentre outras variáveis difíceis de identificar sem o uso da modelagem cartográfica.

As obtenções de indicadores espacialmente explícitos possibilitam a identificação dos processos de degradação das pastagens, constituindo um instrumento de alta relevância para subsidiar ações e projetos de recuperação das pastagens avaliadas. A interpretação das informações geradas permite ainda inferir sobre o estado geral das áreas consideradas degradadas e sua relação com outros fatores não analisados neste estudo, sugerindo-se que o fator que potencialmente mais influenciou no nível de degradação foi o manejo das pastagens adotado pelos pecuaristas da região (GALDINO et al., 2015).

Tabela 2 - Resumo quantitativo do uso e ocupação do solo no município de Pombal, Paraíba no ano de 2002.

\begin{tabular}{llll}
\hline Classe Temática & Área Total $\left(\mathrm{Km}^{2}\right)$ & Área Total (hectare) & $\%$ da área Total \\
\hline Água & 4,5 & 447,0 & 0,5 \\
Agricultura Irrigada & 37,7 & $3.871,5$ & 4,2 \\
Caatinga Estépica Florestada & 48,1 & $4.816,1$ & 5,4 \\
Caatinga Estépica Arborizada & 364,5 & $36.446,7$ & 41,1 \\
Afloramento & 2,4 & 242,2 & 0,3 \\
Zona Urbana & 121,4 & $12.136,0$ & 13,7 \\
Agropecuária & 308,8 & $30.877,2$ & 34,8 \\
Total & 887,4 & $88.836,7$ & 100
\end{tabular}

Com base na técnica de sobreposição e análise espacial, constatou-se que entre os anos de 2002/2012 4,2\% das áreas de Caatinga Densa ou Estépica Florestada, 19,2 \% da Caatinga Rala ou Estépica Arborizada, 14,4\% da Agropecuária e 1,3\% foram mantidas. 20,1\% da Caatinga Estépica Florestada sofreu desmatamento, a redução dessa cobertura está ligada principalmente pela pressão antrópica para a implantação de pastagens e áreas agrícolas, as quais tiveram um crescimento das pastagens e das áreas destinadas aos cultivos agrícolas, conforme evidenciado por (BOLFE et al., 2008).

Houve um crescimento das atividades agropecuárias de $20,3 \%$, e $3,1 \%$ da Agricultura Irrigada ao longo das margens dos rios Piancó e Piranhas. A Caatinga Estépica Arborizada e Florestada avançaram 23,0 \% sobre as demais coberturas e uso do solo, além $3,8 \%$ de áreas sofreram regeneração, essas áreas apresentavam ocupação por agropecuária, solo exposto e no ano de 2012 passaram a apresentar cobertura vegetal (Tabela 3).

Melo Neto et al (2012), observaram que o elevado grau de degradação das áreas cobertas com vegetação nativa, ocorrem devido ao avanço das atividades agrícolas, além de uma elevada fragmentação da vegetação natural, causando uma perda da biodiversidade. Outro aspecto das áreas (agricultura e pastagens) é uma maior heterogeneidade da paisagem, também caracterizado pela fragmentação da paisagem, como as mudanças e a maior diversificação das culturas agrícolas (BOLFE et al., 2008).

Após a instalação do PIVAS, Programa de Irrigação das Várzeas de Souza, o território do município apresentou essas características de crescimento da área irrigada, e diversificação das atividades agrícolas e pecuárias, consequentemente, e a falta de práticas agrícolas adequadas intensificaram os processos erosivos.

Desta forma, é importante que as áreas que apresentaram tendência a riscos de desertificação sejam monitoradas, com ações pontuais com fim de minimizar esses riscos, com o fortalecimento de políticas públicas voltadas para a sustentabilidade socioeconômica e ambiental desse importante ecossistema (FERNANDES et al., 2013). 
Tabela 3 - Resumo quantitativo da dinâmica da paisagem da no município de Pombal, Paraíba.

\begin{tabular}{llll}
\hline Classe Temática & Área Total $\left(\mathrm{Km}^{2}\right)$ & Área Total (hectare) & $\%$ da área Total \\
\hline Caatinga Densa Mantida & 38,1 & $3.812,4$ & 4,2 \\
Caatinga Rala Mantida & 170,2 & $17.023,0$ & 19,2 \\
Agropecuária Mantida & 128,1 & $12.814,8$ & 14,4 \\
Afloramentos Mantidos & 0,0 & 5,0 & 0,0 \\
Crescimento Agricultura Irrigada & 27,2 & $2.717,1$ & 3,1 \\
Água & 5,9 & 588,5 & 0,7 \\
Zona Urbana Mantida & 19,5 & $1.952,9$ & 2,2 \\
Crescimento Caatinga & 203,9 & $20.387,7$ & 23,0 \\
Regeneração & 33,5 & $3.346,8$ & 3,8 \\
Agricultura Irrigada Mantida & 11,3 & $1.132,2$ & 1,3 \\
Crescimento Agropecuário & 180,6 & $18.058,7$ & 20,3 \\
Crescimento Afloramento & 2,4 & 237,9 & 0,3 \\
Crescimento Zona Urbana & 67,0 & $6.692,8$ & 7,5 \\
Total & 887,7 & $88.769,8$ & 100
\end{tabular}

Também observamos que o perímetro urbano sofreu crescimento e consequentemente, o seu raio de ação foi intensificado, marcando o entorno da cidade com áreas descobertas e degradadas. A Zona Urbana, Afloramentos e as áreas degradadas em torno de Pombal Cresceram 7,8 \%, conforme observamos essas mudanças na Figura 3.

Pode-se evidenciar uma perda da cobertura vegetal, o que caracteriza com prejudicial ao ambiente, de acordo com (Benedito, 2001 Apud Batista Junior \& Almeida) a vegetação protege o solo contra erosões, ou seja, contribui para a preservação do solo e seus atributos. A preservação da cobertura florestal promove a conservação da biodiversidade.

$\mathrm{O}$ estudo de imagens multitemporais é muito utilizada para detecção de mudanças ocorridas na cobertura do solo devido às suas particularidades, como a técnica poderosa no realce de imagens, no entanto, o método apresenta uma limitação principal, relacionado com sua capacidade de distinguir entre verdadeira mudança e variabilidade natural. Dessa forma, torna-se necessário o emprego de alguma técnica auxiliar, como a classificação digital de imagens, que complementa o estudo e fornece os dados necessários para uma análise de mudança na cobertura e no uso do solo (NERY et al., 2014).

Diante da problemática do desmatamento na Caatinga, o monitoramento da perda de cobertura florestal se torna importante no que diz respeito à obtenção de informações que subsidiem as tomadas de decisões que visam à proteção e conservação deste bioma. Uma das alternativas para se obter tais informações, é o uso de técnicas de sensoriamento remoto que tratam os dados em uma escala espaço-temporal que satisfaz as premissas dos programas que visam a conservação ambiental (NERY et al., 2014).

A pecuária exerce uma pressão média na área de estudo. A redução de vegetação natural remanescente na área entre os anos de 1988 e 2007 apontou um agravamento ainda maior do estado de conectividade e percolação da paisagem local e a maior parte dos fragmentos ali existentes possuem grandes chances de ser extintos, uma vez que cerca de $80 \%$ da redução total de fragmentos vegetativos observados entre as duas épocas estudas possuem área diminuta e pouca ou nenhuma chance de se autosustentar (OLIVEIRA; SILVA, 2009).

A recuperação da vegetação está condicionada na intenção de utilizar os resultados de estudos e pesquisas que apontam algumas soluções para contenção da degradação que se instala nas áreas através das atividades humanas. As pressões estabelecidas pelo antropismo sobre o meio natural acarretam em processos de substituição dos elementos naturais por elementos oriundos das atividades econômicas, nesse caso o meio natural tem sido visto exclusivamente como uma dádiva, em que aparentemente a natureza é capaz de recompor o que lhe foi tirado (BARROS et al., 2007).

Mesmo com a rugosidade acentuada do modelado que compõe o relevo local se constituindo como um fator de impedimento à atividade agropastoril, essa atividade é realizada sem o cuidado efetivo, tendo em vista que a cultura local não foi incentivada a se adequar ao melhor uso e manuseio das vertentes (BARROS et al., 2007).

É importante salientar que para o empreendimento de uma possível recuperação da floresta nessas áreas, é necessário considerar as áreas abandonadas, as quais se derem continuidade ao processo de regeneração natural sem a intervenção econômica, em alguns anos estarão recuperadas e o balanço do patrimônio dessa floresta possivelmente apresentará um saldo positivo. Isso irá refletir em vários aspectos ambientais iniciando pela flora, atingindo a fauna, que possuirá áreas maiores buscando a sobrevivência e culminando em outros processos naturais que afetam direta e indiretamente a população humana, como a contenção dos desmoronamentos de encostas e a retenção de água na serrapilheira que regulará o fluxo hídrico dos riachos nascidos naquela porção do território paraibano (BARROS et al., 2007). 
Figura 3 - Dinâmica da Paisagem de Pombal-PB no período entre 2002-2012.

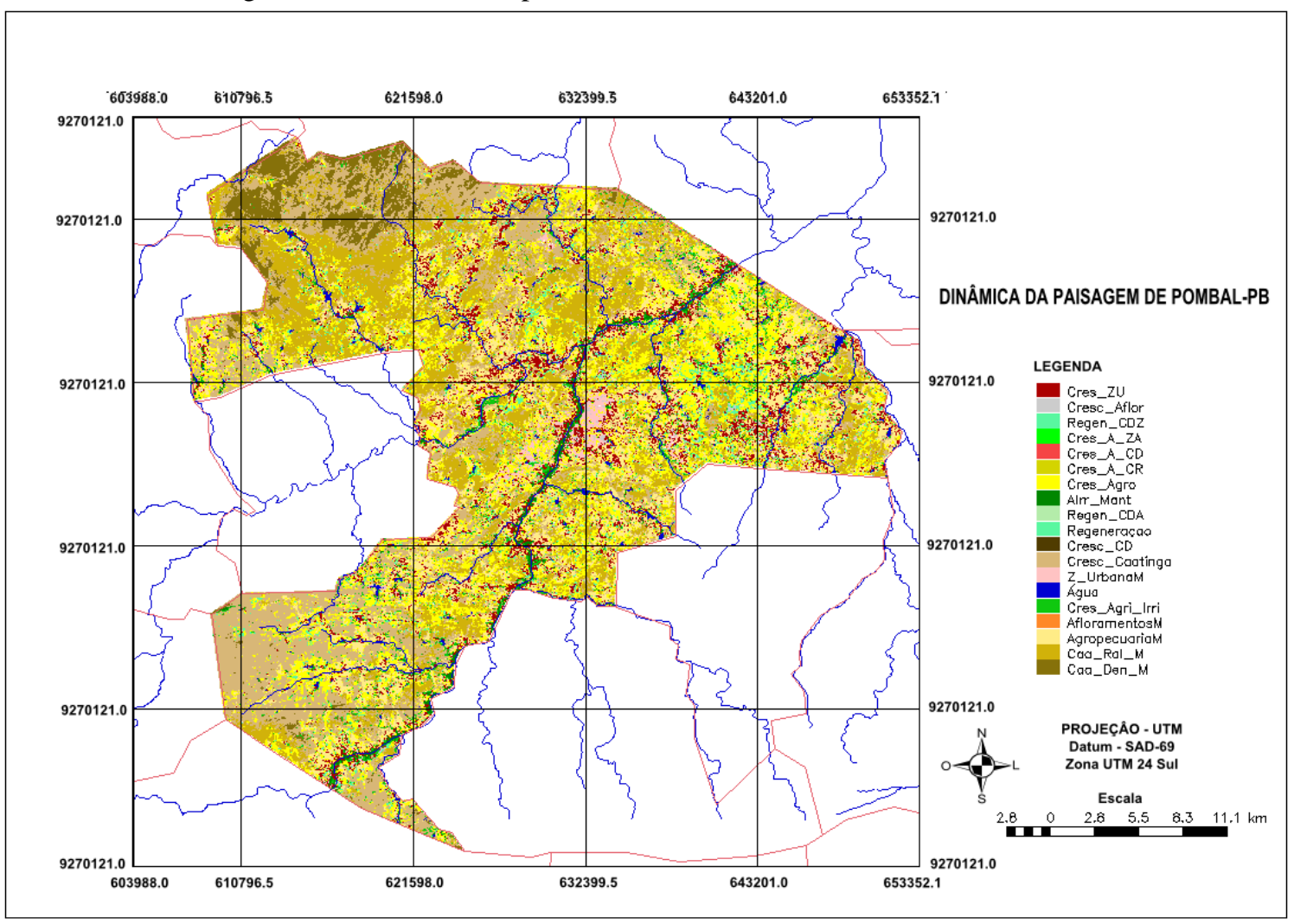

\section{CONCLUSÕES}

Nos anos analisados verificou-se que houve um decréscimo da cobertura vegetal e sua substituição por atividades agropecuárias, o que é altamente prejudicial, também se observou um aumento das áreas degradadas.

No decorrer da dinâmica espacial e temporal, a qualidade da paisagem teve uma sensível piora em termos ambientais, o que foi determinado pelo aumento das áreas com solo exposto degradado e aumento do nível de alterações antrópicas.

Os resultados mostraram que o município necessita de medidas de controle do desmatamento e recuperação de áreas degradadas.

\section{REFERÊNCIAS BIBLIOGRÁFICAS}

ALMEIDA, J. S.; NASCIMENTO, K. N. F. do.; PEREIRA, R. A.; MELO, W. F. Dinâmica de uso das terras no município de Pombal - PB. V Jornada Nacional da Agroindústria, Bananeiras - PB, 06-09 de Novembro de 2012.

BARBOSA JÚNIOR, J. S.; ALMEIDA, A. S. Análise multitemporal com a utilização da técnica de sensoriamento remoto e geoprocessamento no município de Bonito - Pará. III Simpósio Brasileiro de Ciências Geodésicas e Tecnologias da Geoinformação, Recife PE, 27-30 de Julho de 2010.

BARROS, M. J. V; ANDRADE, L. A.; ROSA, P. R. Diagnóstico ambiental dos fragmentos florestais do município de Areia-PB nos anos de 1986 e 2001.
Geografia -v. 16, n. 2, jul./dez. 2007 - Universidade Estadual de Londrina, Departamento de Geociências.

BRASIL. MINISTÉRIO DAS MINAS E ENERGIA. Projeto cadastro de fontes de abastecimento por água subterrânea. Diagnóstico do município Pombal, estado da Paraíba. Recife: CPRM, 2005. Disponível em: < http://www.cprm.gov.br/rehi/atlas/paraiba/relatorios/POM B147.pdf> Acessado em: 25 de Janeiro de 2015

BOLFE, E. L.; BOLFE, A. P. F.; SIQUEIRA, E. R. Dinâmica do uso e ocupação do solo: subsídio recuperação de áreas degradadas em Japaratuba, SE. Geomática, Santa Maria, v. 3, n. 1 e 2, 2008.

CÂMARA, G.; SOUZA， R. C. M.; FREITAS, U. M.; GRARRIDO, J. SPRING: Integrating remote sensing and GIS by object-oriented data modeling. Computers \& Graphics, 20: (3) 395-403. May-Jun, 1996.

DÉSTRO, G. F. G.; CAMPOS, S. SIG-SPRING na caracterização do uso dos solos a partir de imagens do satélite CBERS. Engenharia Agrícola, 21(4): 28-35 (2006).

FERNANDES, M. de F.; BARBOSA, M. P.; NETO, J. M. de M. Caracterização do Uso das Terras e das Áreas em Riscos de Desertificação em Parte da Floresta Nacional do Araripe (FLONA): Municípios de Barbalha e do Crato, Estado do Ceará. Revista Brasileira de Geografia Física v.06, n.05 (2013) 1476-1498. 
FERREIRA, A. B. E FILHO, W. P. Análise do uso e cobertura da terra de três sub-bacias hidrográficas - Rio Grande do Sul/Brasil. RBGF- Revista Brasileira de Geografia Física Recife-PE, Vol.2, n.03, set-dez, 2009, 20-36.

GALDINO, S.; BOLFE, E. L; NOGUEIRA, S. F.; SPINELLI-ARAUJO, L.; VICTORIA, D. C.; GREGO, C. R.; BAYMA-SILVA, G. Análise geoespacial entre níveis de degradação de pastagens e parâmetros físicos em subbacias de Pindamonhangaba, SP. Anais XVII Simpósio Brasileiro de Sensoriamento Remoto - SBSR, João Pessoa-PB, Brasil, 25 a 29 de abril de 2015, INPE.

INPE. São José dos Campos: ResourceSAT LIS3, 2012. Imagem de satélite: 04 de Novembro de 2012. TIFF: 53,8 $\mathrm{Mb}$, Canais 2, 3 e 4.

KLEINPAUL, J. J. et. al. Análise Multitemporal da Cobertura Florestal da Microbacia do Arroio Grande, Santa Maria, RS. Bol. Pesq. Fl., Colombo, n. 51, p.171-174. Jul./dez. 2005 .

LEITE, M. E.; FERREIRA, M. F. F. Análise EspaçoTemporal do Uso da Terra na Bacia Hidrográfica do Rio Tabuas, Norte de Minas Gerais, com Aplicação das Geotecnologias. Revista Brasileira de Geografia Física V.06, N.02 (2013) 184-194.

MELO NETO, J. O.; GUIMARÃES, D. V.; GONZAGA, M. I. S. Estimativa e análise temporal do uso e ocupação do solo no entorno do refúgio de vida silvestre Mata do Junco com base em processamento digital de imagens orbitais. Scientia Plena, v. 8, nº 4, 2012.

MOREIRA, A. A.; ALMEIDA, R. P.; FERNANDES, F. H. S.; NERY, C. V. M. O Algoritmo Support Vector
Machine aplicado ao Mapeamento do Uso e Ocupação do Solo. Revista Brasileira de Geografia Física V. 07 N. 02 (2014) 291-303.

NASA. Landsat TM 7. Estados Unidos da América: NASA, 2000. Imagem de satélite: 10 de Fevereiro de 2000.TIFF: $53,8 \mathrm{Mb}$, Canais 3, 4 e 5.

NERY, C. V. M.; MOREIRA, A. A.; FERNANDES, F. H. S.; ALMEIDA, R. P. Uso do Sensoriamento Remoto na Detecção de Mudança na Microrregião de Montes Claros/MG. Revista Brasileira de Geografia Física, v.07, n.01 (2014), 130-145.

OKA-FIORI, C.; FIORI, A. P.; HASUI, Y. Dinâmica da ocupação do solo da bacia do Rio Itiquira, Mato Grosso, Brasil. Revista Ra'e Ga, 7:19-31 (2003).

SOARES. S. C. et. al. Mapeamento e análise multitemporal do uso e ocupação do solo em região do município de Santarém-PA através de imagens Landsat 5-TM. Anais XVSBSR, Curitiba-PR, Abril/Maio de 2011, INPE, p. 6910.

ROSA, R. Introdução ao sensoriamento remoto. 4 ed., Uberlândia, Editora da Universidade Federal de Uberlândia, 210p. (2001).

VIANA, M. Virgílio; PINHEIRO, L. A. F. V. Conservação da biodiversidade em fragmentos florestais. Série Técnica IPEF v.12 nº. 32, p25-42, dez. 1998.

OLIVEIRA, D. S. de.; SILVA, A. M. da. Cobertura do solo e fragmentação da vegetação natural do município de Conquista - MG em 1988 e 2007. REA - Revista de estudos ambientais v.11, n. 1, p. 61-70, jan./jun. 2009. 